\title{
An overview of electronic information resources sharing initiatives in Kenyan universities
}

\author{
Daniel C. Rotich' \\ Department of Publishing and Media Studies, School of Information Sciences, \\ Moi University, P.O. Box 3900, Eldoret, Kenya. \\ dcrotich@hotmail.com
}

and

Evans M. Munge ${ }^{2}$

Moi University library, P.O. Box 3900, Eldoret, Kenya.

mungemwangi@yahoo.co.uk

\begin{abstract}
Received: 5 th June 2006
Accepted: 10th November 2006

Information professionals in Kenya have long been cognisant of the need to share and transfer information among themselves. Unfortunately, information resource sharing initiatives have been limited to inter-library loans (ILL) ventures which have also not been very successful. Some of the reasons for failure have been: insufficient information resources for sharing, inadequate budget allocation to cater for the high costs of information resources, and the lack of appropriate communication infrastructure and enabling technologies to support any meaningful venture considering that most libraries in Kenya have been operating on manual systems.

The widespread use of information and communication technologies (ICTs) in Kenya since the 1990s has, however, enabled the realisation of a number of information sharing initiatives among libraries and information centres. This paper examines successes and/or failures of such initiatives among Kenyan universities in relation to the objectives for which they were intended to fulfil, arguing that progress can be achieved much more easily by focusing future efforts toward building on the successes, and avoiding the pitfalls that have been experienced.

It is concluded that although on-line information sharing networks are not a panacea to all the problems facing information providers in Kenyan universities, they have, nevertheless, potential to open new avenues, enabling users to have access to vast information resources available within national and international databases, as a way of alleviating information scarcity in these institutions.
\end{abstract}

Key words: Kenya, information resources sharing, information networking

\section{Introduction}

Resource sharing, while seen in the context of librarianship, is an omnibus expression to cover co-operation, coordination, inter-library loans, co-operative acquisitions, co-operative storage and processing (Odini, 1991). Following this reasoning it can be argued that information resources sharing is a wide phrase embracing information services cooperation, systems, and networking. This is in agreement with Odini's ( $|99|$ ) assertion that resource sharing may be seen as a term for working out inter-institutional relationships for the benefit of users in a profession which is frequently described as changing from materials-oriented to client-oriented.

Information professionals in Kenya realized that they can not manage to acquire all the information resources their institutions require, and also, as a result of the information explosion, the amount of information generated is so enormous as to render its complete collection by one institution impossible. Hence the need to share and transfer information among themselves. Unfortunately, information resource sharing initiatives in Kenya's libraries and information centers have been limited to inter-library loans (ILL) ventures mostly among libraries of similar genealogy (for example, special libraries, academic libraries, and so on), and even these have had more failures than successes.

Among the reasons for failures have been: lack of institutional policies or obligations relating to resource sharing, insufficient information resources for sharing, inadequate budget allocation to cater for the high costs of resources, and lack of appropriate communication infrastructure and enabling technologies. In other words, there has been inefficient application of the concept of resource sharing in Kenya (Were, 2004).

This paper provides an overview of the current situation of existing initiatives, focusing especially on their successes and/or failures in relation to the objectives which they were intended to fulfil, so that in future efforts will be focused

I. Daniel Rotich, PhD, is Head of the Department of Publishing and Media Studies, School of Information Sciences, Moi University, Kenya.

2. Evans Munge is Librarian, Moi University Library, Moi University, Kenya. 
toward building on the successes and avoiding the pitfalls that have been experienced. Much of this information has been garnered from the authors' own experiences, either as information services providers or as information sciences educators in the Kenyan university scene, backed by information available in the professional literature and also from contacts within the library and information science network in Kenya.

\section{Overview of universities in Kenya}

In the context of this paper, universities are those institutions have been authorized to offer university education in Kenya through accreditation by the Commission for Higher Education (CHE). According to CHE (2006), Kenya currently has 23 universities, of which 6 are public (that is, those established by Acts of Parliament) and the rest are private. The public chartered universities are:

- University of Nairobi. Established in 1956 as the Royal Technical College, it became the first national university in Kenya in 1970. It is the largest university in the country;

- Moi University. It was established in 1984 as the second public university in Kenya. It also has a constituent college, the Western University College of Science and Technology (WUCST), which was established in 2002;

- Kenyatta University. Established in 1965 as Kenyatta College, offering courses in secondary and teacher education. It was made a full-fledged university in 1985;

- Egerton University. It was founded in 1939 as a school for training white European youth for careers in agriculture. It achieved university status in 1987;

- Jomo Kenyatta University of Agriculture and Technology. It started operations in I98I as a diploma awarding institution in the fields of agriculture and engineering. It became a full-fledged university in 1994, and

- Maseno University. Began as a government training institute in the 1980s, became a constituent college of Moi University before achieving full university status in 2001 .

The private universities are those established in accordance with the Universities Act, 1985 and University Rules, 1989. They fall into three categories: chartered, registered, and universities operating under Letters of Interim Authority. The private chartered universities (and the years they were granted charters) are: University of Eastern Africa, Baraton (1978); Catholic University of Eastern Africa (1992); African Nazarene University (1993); Daystar University (1994); Scott Theological College (1997); United States International University (1999); Aga Khan University (2002), and Kenya Methodist University (2006).

The registered universities are those that were offering degrees before the establishment of CHE and were issued with a Certificate of Registration after fulfilling the requirements set out in the Universities Rules, 1989. These institutions, which were all registered in the 1980s, are: the Kenya Highlands Bible College; the Nairobi Evangelical Graduate School of Theology; the Nairobi International School of Theology; the Pan Africa Christian College, and St Paul's Theological College. $\mathrm{CHE}$ is working with these institutions towards the award of charters.

The universities operating under Letters of Interim Authority are those that have applied to CHE for their establishment and fulfilled requirements as stipulated in the Universities Rules, 1989, even though they are yet to be awarded charters. All these were either established or upgraded to university status between 2000 and 2002, and are Kabarak University; Kiriri Women's University of Science and Technology; Strathmore University, and the East African School of Theology.

The majority of these institutions are located in Nairobi Province ( 2 public and II private), followed by Rift Valley ( 2 public and 4 private), Central Provice (I private and I public). Nyanza and Eastern each have one, public and private respectively.

\section{Information resources sharing in the electronic age}

With the widespread use of computers and related technologies in Kenya in the 1990s, information processing organisations began to use information and communication technologies (ICTs) to enhance the hitherto moribund information resource sharing initiatives. Several factors have contributed to the need for electronic networks for on-line information sharing in Kenya.

One of these is the critical need for access to, and sharing locally and internationally available information resources. The increase in the value and demand of information which continues to exert pressure on libraries to offer more effective service to their users, has also been gradually leading to a shift in focus from the need for accumulation and ownership of information resources to providing access (Wanyoike, 2004).

There has also been the recognition and appreciation, as in information environments in other parts of the world, of the emergence of a sophisticated 'new' class of clients with diverse information needs that require to be satisfied (Ocholla, 1995). Information processing organisations in Kenya have thus been compelled to use new technologies such as ICTs to enhance service delivery, especially through information sharing.

SA JnI Libs \& Info Sci 2007, 73(I) 


\section{Existing collaborative information networks}

ICTs have enabled a number of information sharing initiatives among Kenyan universities, most of which proliferated in the 1990s and early 2000. In many of the universities, the services provided by the initiatives are channelled through the university libraries as opposed to the university as a whole. This is due to a number of reasons.

First, the university libraries have been more directly involved in the initiation and implementation of the initiatives, and therefore they are seen as the 'natural' home of the initiatives. Secondly, libraries are the most centrally located to provide facilities where majority of the university community can access the e-resources. Thirdly, the majority of the target users do not have adequate search (as well as ICT) skills to enable them fully exploit these resources, and so they look up to the library staff to provide this expertise.

This section provides a brief profile of the major networks that have had a big impact on information resources sharing and a description of the level of their collaboration.

The African Virtual University

The African Virtual University (AVU) was launched in 1997 through World Bank funding. Its objective is to provide students and professionals in Africa with access to some of the highest quality learning resources from around the world through the use of modern information and communication technologies (AVU, 2005). This 'university without walls' has been using satellite technology to deliver distance education at over 57 learning centres in 27 African countries. This has enabled higher education institutions to supplement their existing programmes with resources of a global virtual university.

In Kenya, Kenyatta and Egerton Universities are the key institutions participating in this undertaking, which by 2003 had evolved from a project of the World Bank to an independent non-profit making organization with headquarters in Nairobi, Kenya. Other universities, however, are also working towards integrating the AVU into their programmes. For example, Moi University has recently appointed a senior member of staff to spearhead the rollout of the AVU programme in the institution. There is no doubt that this trend will catch on quite fast as institutions of higher learning in Kenya realise that the use of ICT tools for learning and teaching, especially in distance education, is likely to become more widespread. This will necessitate students and faculty becoming more and more exposed to online information resources.

The African Virtual Library - Kenya

The African Virtual Library - Kenya Chapter (AVL-K) was launched in 1999 as the African Virtual Library Initiative (AVL-I) by a forum of stakeholders - librarians and information technology specialists in Kenyan institutions - meeting under the auspices of the Kenya Institute of Management (KIM). The mission of the African Virtual Library Initiative (AVL-I) itself is

to facilitate the provision of bibliographical and other information online services that meet the needs of educational, research and development work in Eastern Africa, with a view to developing linkages with other regional initiatives to create a truly African virtual library (Internet Foundation of Kenya, 2002).

Against this background, AVL-K was born with the aim of supporting Kenyan libraries' automation, Internet connectivity and networking in order to mobilize the partners (mainly academic and public libraries) to convert their resources into electronic format for online information sharing partnership. Some of the programme's objectives that have a bearing on information resources activities include:

- Assisting libraries to automate and put their holdings in an MARC format to aid in establishing a web-based union catalogue;

- Training in IT skills to enable personnel in member institutions to participate fully in the information technology environment, and

- Promoting networking among the participants for the purpose of on-line information sharing (Wanyoike, 2004).

Currently, the AVL-K project has 30 stakeholders, comprising institutions of higher and intermediate education in the public and private sector, public libraries and documentation centres, and research institutions, among others. All the chartered universities are members of AVL-K. These stakeholders are involved in several activities which are intended to help AVL- $K$ achieve its objectives, among them the following:

- Automating libraries in order to facilitate networking for online information sharing;

- Converting library catalogue records to conform with agreed MARC format to help in establishing an electronic union catalogue;

- Formulating electronic information sharing policy guidelines;

- Establishing sustainable Internet/e-mail connectivity;

- Establishing institutional websites, and

- Planning for the development of community information centres that can be used to transfer information to rural areas in Kenya. 
Kenya National Education Network

The Kenya Education Network (KENET) is part of the U.S. government-funded Leland Initiative that works to extend full Internet connectivity to African countries in order to promote sustainable development. KENET's goal is to:

establish sustainable communication and networking among educational institutions in Kenya that will facilitate wide use of Internet technology in teaching, research and sharing of other information resources to the general populace at affordable cost (KENET, 1999).

The Leland Initiative Memorandum of Understanding was signed in 1999 between the Kenya and US governments mandating the Initiative to establish and enhance Internet services for education and to promote information resources sharing among stakeholders for the benefit of the academic community in Kenya. In this respect, the project's goal is highly consistent with AVL-K's core objective of networking Kenyan libraries for the purpose of on-line information sharing (Wanyoike, 2004).

The broad objectives of the project (KENET, 1999) include:

- Setting up a cost-effective and sustainable private network with high-speed access to the global Internet;

- Facilitating electronic communications among students and faculty in member institutions;

- Sharing teaching and learning resources;

- Providing a platform and infrastructure for electronic teaching and learning, and

- Collaborating in research and development of educational content.

In order to fulfil these objectives, KENET began by applying and being granted a licence by the Communications Commission of Kenya to build and operate an education network, and further to operate as an Internet Service Provider (ISP). This means that KENET, whose secretariat is located at the University of Nairobi's Jomo Kenyatta Memorial Library, could establish and manage its own private network to carry both voice and data.

KENET was designed to have a very wide focus comprising universities, professional training institutes, post secondary training institutions, schools, research institutes and libraries, with Telkom Kenya (a government owned parastatal with monopoly in telecommunication business) as a facilitating partner. Indeed, by the end of 2004 this electronic network had managed (with donor funding) to connect close to 50 institutions, among them all the public and private chartered universities, as well as three of the ten other categories of private universities (Thairu, 2004).

Program for Enhancement of Research Information

The Program for Enhancement of Research Information (PERI) is managed by the International Network for the Availability of Scientific Publications (INASP) and is designed to support capacity building in the research sector in developing and transitional countries by strengthening the production, access and dissemination of information and knowledge (INASP, 2005). INASP is itself a co-operative network of partners whose aim is to enhance world-wide access to information and knowledge. PERl's objectives are to:

- Facilitate the acquisition of international and local information and knowledge

- Improve access to local research through the improved preparation, production and management of local journals

- Provide awareness or training in the use, evaluation and management of electronic information and communication technologies (ICTs)

- Support problem-solving of regional and local information access and dissemination challenges.

PERI endeavours to achieve these objectives through five interlinked and complementary components, each with its own goal and objectives. The components are delivering information; strengthening national research publications; supporting country collaboration and networking; enhancing ICT skills, and research and development. Whereas all these components can be seen to promote access to information resources, the first three components are of particular significance to information resource sharing in institutions of higher learning in Kenya.

All the chartered universities are partners in this INASP-managed co-operative network.

\section{Electronic Supply of Academic Publications}

The Electronic Supply of Academic Publications (eSAP) project is a joint effort of the International Association of University Presidents (IAUP) in cooperation with the International Federation of Catholic Universities (IFCU). Its aim is to set up a sustainable electronic document delivery system for scholarly publications between universities in the North and the South as well as between the universities in the South themselves, by means of the Internet, and thus assist in the supply of academic publications to as well as from the developing world (IFCU, 2005).

The project dates back to 1997 when the idea of a possible co-operation project between IAUP and IFCU in the field of academic information supply by means of Internet, was mooted at the mid-term conference of the International Association of Universities. The idea crystallised into a viable project through discussions at subsequent meetings, culminating into a Memorandum of Understanding between the IAUP and participating East African universities, which was signed in February 2001.

SA Jnl Libs \& Info Sci 2007, 73(I) 
The project is founded on the major belief that access to the international academic resources on the Internet has two core aspects: availability of resources, and knowledge and skills to use the online resources optimally. eSAP believes that the first aspect is adequately addressed by programmes such as INASP and is thus focused more on the second aspect, especially in providing training for academicians. According to Simons (200I) eSAP relates success by partner universities on several theoretical points of departure, including the following:

- Co-operation between universities will increasingly rely on clusters and networks in which one of the key success factors will be sharing of resources;

- In order for universities in developing regions to become more of producers rather than just 'receivers' of academic information, they have to cooperate in acquiring, managing, publishing and distributing information, and

- Electronic communication, particularly the Internet, will rapidly become the main means for transfer and exchange of academic information.

These assumptions have in turn set the agenda for each member university to undertake to fulfil a number of responsibilities, among them the following:

- Manage and make available its proportional share of the academic journals jointly possessed by the cluster;

- Electronic document delivery of articles from these journals to other members;

- Electronically publish the output from its own academic staff members (articles, papers) on the Internet server of the project, and

- Create and maintain the databases needed for the information awareness services (including bibliographic catalogue databases, experts database).

In Kenya, only three universities so far are party to this project: the Catholic University of East Africa, Kenyatta University, and the University of Nairobi.

Database of African Theses and Dissertations

For a long time, the vast bulk of research conducted in Africa has remained as grey literature and has thus remained effectively lost (Sturges and Neill, 1998). There has been a great need, therefore, for developing a mechanism whereby the collection, management and electronic dissemination of African theses and dissertations could be enhanced. These issues were discussed at a meeting organized by the Project for Information Access and Connectivity (PIAC) held in Nairobi, Kenya, in January 1998. The meeting recommended a feasibility study (undertaken between 1998-1999) for a pilot project (carried out between 2000 - 2003) to index, abstract, and distribute theses and dissertations completed in African universities.

This gave rise to the Database of African Theses and Dissertations (DATAD) initiative, an affiliation of the Association of African Universities (AAU). DATAD seeks to collaborate with African institutions to make research output from Africa accessible to researchers and scholars in Africa and other parts of the world. The following are among the programme's long-term objectives (AAU, 200I) which have a strong component of information resources sharing:

- Working with participating institutions to build a regional database of theses and dissertations;

- Creating capacity in African universities for the collection, management and dissemination of theses and dissertations electronically;

- Providing visibility and improving accessibility to the work of African scholars both within and outside of the continent, and

- Promoting cooperation among member universities and networking of institutions.

DATAD advocates a combination of both centralized and decentralized architecture at management and technical levels, which was found most acceptable by institutions and technically feasible given the relatively poor and unreliable ICT infrastructure in most parts of Africa (Materu-Behitsa, 2004).. The centralised activities and processes are concerned with standards, quality control, and coordination, while the decentralised ones are related to data entry, institutional quality control; storage and archiving; provision of full text, and copyright and intellectual property rights management.

Of the II pioneering institutions, only Kenyatta University from Kenya is a partner in DATAD.

Inter-University Council for East Africa

The primary responsibility of the Inter-University Council for East Africa (IUCEA) is to co-ordinate academic research activities for member universities and governments. Its mission is to encourage and develop mutually beneficial collaboration between its member universities, and between them and the governments and other organizations, both public and private. Such collaboration includes resource sharing.

A preliminary review of the core functions of IUCEA and needs assessment among institutions was undertaken, and one of the areas identified for funding was co-publishing, publications and sharing of information through the electronic and print media (IUCEA, 2004). This was partly because of the realisation that there can be no proper co-ordination and implementation of research activities without access to information resources.

SA JnI Libs \& Info Sci 2007, 73(I) 
An important outcome of this process is the East African Network of University Libraries (EANUL) which is designed to help university libraries in East Africa to meet and share experiences, and extend these experiences to their counterparts elsewhere in Africa (IUCEA, 2005). EANUL functions in three chapters for the respective countries. It is expected that when fully operational, EANUL will enable universities in the East Africa region to have an important initiative that will support information resource sharing activities within and among them.

Another important component of information sharing among IUCEA member states is the Africa Learning Network (ALN) created by the United Nations Economic Commission for Africa (UNECA) to facilitate the improvement of ICTs in the learning and teaching process. One of the three pillars of ALN is VarsityNet, which establishes connectivity at universities and related institutions of higher learning and research, and stimulates the development of content production and information sharing within this environment (Ayoo, 2005). In line with information sharing concerns, one of the key aims of VarsityNet is creating the necessary conditions for generating knowledge, which is produced on Africaspecific conditions in the information society for teaching and learning purposes. Currently, all chartered universities in Kenya are members of IUCEA (IUCEA, 2005).

Kenya Libraries and Information Services Consortium

The Kenya Libraries and Information Services Consortium (KLISC) had its humble beginning at a regional meeting of the Inter-University Council of East Africa Libraries in 1998. This led to the idea of establishing an academic and research libraries consortia, which was mooted at a Kenya University Librarians Committee (KULC) meeting held in 2003 in Nairobi.

After discussions in subsequent meetings, the consortium was finally inaugurated at a KULC seminar held in June 2004 and a constitution of the consortium unveiled. The consortium's secretariat is located in the Jomo Kenyatta Memorial Library at the University of Nairobi. Though initially it was intended for academic and research libraries, its membership has widened to include public libraries, archives, and museums. The objectives of KLISC which have a bearing on information resource sharing are to:

- Develop and improve cooperation and understanding among member libraries;

- Provide a forum for sharing information and experiences, and

- Develop cooperative acquisition schemes among members.

In attempting to achieve these objectives, the consortium envisages to move libraries from hardcopy to electronic environment, strengthen access to information through use of ICTs, as well as sensitise and educate librarians, users and managers on modern technological methods of accessing information (Were, 2004). Other activities will include:

- Carrying out research studies, projects and programs leading to knowledge of available resources and services;

- Supporting the implementation of systems and techniques that will facilitate increased cooperation among member libraries, and

- Establishing networks for the development of content, creation of digital libraries and delivery of documents to library users.

This initiative is still in its formative stages, although progress is slowly being made with regard to popularising it to the respective member institutions' authorities. It is, nevertheless, expected that being the only indigenous e-initiative so far launched and with commitment from all members, it will attract goodwill from all those who are expected to support it.

\section{Major achievements}

The overarching objective of all these initiatives is no doubt the enhancement of access to nationally and internationally available electronic information resources by participating institutions. Each of these initiatives have certain unique features that are significant to our discussion and which point to some of the successes that have been realized with regard to achieving the core objective. In general, however, we have chosen to discuss the successes achieved so far from the point of view of the following four main areas:

- Assisting libraries to automate as a prerequisite for online information sharing;

- Facilitating the provision of, and access to the collective bibliographic and other electronic information resources held by partner institutions;

- Supporting collaboration and networking among participating institutions; and

- Developing ICTs skills for personnel in member institutions to enable them participate fully in the information technology environment.

These aspects are discussed further in the sections that follow.

Assisting libraries to automate

Automating libraries is one of the prerequisites for online information sharing. The long tradition of using manual systems in many of the libraries in Kenyan universities has necessitated the need for, first and foremost, sensitizing these libraries

SA Jnl Libs \& Info Sci 2007, 73(I) 
on the need to automate so as to enjoy the benefits of networking. Consequently, almost all the existing networks have been involved in this endeavour to some extent or other.

For example, AVL-K has been able to stir up the need among libraries (through meetings and seminars) to focus on a better future in information service through automation (Wanyoike, 2004). In particular, issues such as those concerning basic hardware requirements, selection of library software, configuration of LANs and retrospective conversion of collections, among others, have received a lot consideration. Indeed, as already pointed out, one of AVL-K's secondary objectives which it has been pursuing vigorously is to assist libraries to automate and put their holdings in an MARC format to aid in establishing a web-based union catalogue. Similarly, KENET is also having a big impact on the application of ICTs in Kenya's academic libraries, particularly recognising their importance as depositories of approximately $70 \%$ of all the library resources in the country (Wanyoike, 2004).

Automation has enabled these libraries to take full advantage of the projects' benefits with the result being enhanced value of services delivered as the libraries graduate to online status (Kinyanjui, 2000).

It is obvious to all the libraries in universities in Kenya, be they actual or potential participants in existing electronic networks that collectively such initiatives hold the greatest promise for the future with regard to sharing of information resources. Consequently, provision of the necessary infrastructure, such as automation and Internet connectivity, is not a mater of choice; it is crucial. It is therefore arguable that on this score, these initiatives have played a big role in laying the groundwork for automation of a good number of the libraries and information centres in universities in Kenya.

Facilitating access to electronic information resources

Facilitating access to electronic information resources is a core business of all the existing initiatives. In particular, AVU has been very visible through its digital library programme, launched in 1998 and which was designed to make scientific information available to African students and faculty in participating institutions (Wolff, 2002). Furthermore, AVU has also developed a web-based portal for the African educational community to share African research results (Wolff, 2002). This has been made possible through the use of asynchronous Internet connectivity (Jensen, 1998).

KENET is also unique in that it is both a network and an ISP, and is thus able to provide Internet gateway services for member institutions to access both local and international databases. It has also provided a platform and infrastructure for electronic teaching and learning as well as resource sharing, through hosting educational databases and strategic institutions' web sites. KENET has, therefore, managed to harness knowledge generated in the country for the common good of the cluster and ensured that national information resources are effectively and efficiently used for sustainable development. In order to enhance its value as a premier educational network, KENET is building a portal that will link to the web sites of the individual educational (partner) institutions.

Similarly, the eSAP project facilitates access to academic resources on the Internet (Mayega, 2005). More importantly, it creates the possibility for academicians in developing countries to electronically publish their articles and reports on the Internet thus making their academic works known and available to the world. This means that universities in Kenya are able to order electronic versions of academic publications from their cluster partners (Simons, 200I).

PERI, on the other hand, supports online publishing of national and regional journals, and a vital outcome of this process is the African Journals OnLine (AJOL), which provides access to African published research and increases worldwide knowledge of indigenous scholarship. AJOL provides access to abstracts, sophisticated searching within AJOL titles, document delivery, and email alerts of newly published issues. Consequently, with many researchers now publishing in electronic format in journals that continue to be added to the AJOL list, electronic resource sharing has been facilitated on a very big scale. Similarly, the 'strengthening national research publications' component is geared towards increased dissemination of national and regional research information.

PERI has also developed useful directories and networks through which information activities are 'mapped' and users with queries are either provided with information or are connected to institutions and individuals with relevant expertise. An important resource base is the INASP Directory (see http://www.inasp/info/pubs/directory/) with over 300 detailed profiles of organisations and activities supporting any aspect of production, access to, and dissemination of, information and knowledge.

DATAD's major achievement is the creation of DATAD OnLine (http://www.aau.org/datad/database), the abstracts database with founding records from the II pioneering institutions, which was launched in 2003 (AAU, 2004). By 2005, the database had over 16,000 records and growing. There is evidence that the DATAD initiative has continued to gain acceptance and momentum within institutions as evidenced by the large number of registered users of the database (Materu-Behitsa, 2005). Partner institutions are able to exchange abstracts of theses electronically through DATAD OnLine as well as through DATAD on CD-ROM. This service will be enhanced as more universities begin to contribute toward building the DATAD database. 
Ubogu (2003) also observes that even before the main database was launched, institutions were reporting various roles it was already playing, including as a:

- Research results dissemination tool to give summaries of the findings;

- Networking tool to give the names of authors, supervisors, and their contact information;

- Quality control tool to bring to light the quality of research undertaken in African Universities, and

- Indicator of the research gaps and reduce duplication

These constitute important aspects of information resources sharing. The DATAD initiative has also been involved in laying the groundwork for initiating electronic theses and dissertations (ETDs) projects. The pioneering institutions in particular are now better placed to embark on more extensive ETD projects as well as in information resources sharing initiatives through improved management and provision of access to their collections of theses and dissertations, courtesy of DATAD (Ubogu, 2003). It is also encouraging that DATAD has been focussing more on expansion, sustainability, access, preservation, and copyright and intellectual management in the future. These are intended to ensure long-term availability of the DATAD resources to the contributing as well as the larger research community.

\section{Supporting collaboration and networking}

The information profession is frequently described as changing from materials-oriented to client-oriented, hence the need for strong inter-institutional relationships aimed at addressing the diverse needs of users. Electronic information networks in Kenya have largely been responsible for the achievement of such inter-institutional relationships through library networking and collaboration.

A case in point is the AVU whose business strategy being implemented since 2002 focuses on the project being a facilitator for networking among partner institutions rather than aspiring to be a degree-granting institution (Wolff, 2002). In this respect, use of asynchronous Internet connectivity is significant because this is the technology most suited to virtual distance learning. Furthermore, with the lowering of the costs of connectivity - significantly wide-band satellite-based Internet connections -institutions of higher learning in Kenya will be more likely able to provide enhanced infrastructure to support information resources sharing among AVU's network of partner institutions.

AVL-K has also provided facilitation in this area through support for other initiatives. For example, it actively participated in the planning of the Kenya Education Network (KENET) project by preparing the concept paper, and contributed in the designed of KENET's project document (Kinyanjui, 2000). Such input has made KENET to be one of the most successful of all the existing information resource sharing initiatives. Its objectives have been achieved to a large extent as evidenced by the large number of institutions already connected to the network. Indeed, a poll conducted by the network showed that $83 \%$ of all respondents who use the network's services felt that KENET has provided the information service of choice for many of the members of the academic community seeking appropriate information for their academic and research undertakings (KENET, 1999).

PERI has also been very instrumental in implementation of enhanced mechanisms for information resource sharing in Kenya. Through the 'supporting country collaboration and networking' component, PERI has supported a number of national networking and consortia building activities including the following (INASP, 2005):

- Discussion and collaboration fora. These are intended to provide individual libraries and information centres opportunities to discuss issues unique to them with regard to sharing and building capacities to manage information resources. Such fora include meetings of country coordinators as well as ad hoc meetings, workshops and other events to bring together participants in-country, and

- Negotiation and licensing skills for library networks, where librarians learn skills in managing electronic networks for purchasing, managing and disseminating the resources available.

There has also been significant achievement with regard to co-operative subscription to electronic journals. INASP negotiates with major international publishers on affordable and sustainable access licences. Universities, among other not-for-profit educational and research organizations pay an annual nominal subscription fee in return for low-price access to high-value content. Through this arrangement, made possible by PERl's 'delivering information' component, Kenyan universities have access to thousands of full text journals with virtually no cost at point of use.

PERI looks certain to continue to be an important player in the efforts to develop sustainable networks for information resource sharing among Kenyan universities, in much the same way it has impacted strongly on provision and access to affordable scientific and research information by these institutions.

DATAD's contribution in this regard has been three-fold: development of DATAD LISTSERV, facilitation of meetings and workshops, and developing capacity to provide the DATAD database on CD-ROM. The first two have enabled participants in the DATAD initiative to discuss issues of common concern and find common ground for addressing problems that they individually and collectively face in their attempts to build a sustainable network. Development of 
DATAD on CD-ROM is an important undertaking for those institutions without full Internet connectivity because they are able to provide scholars with access to research information through this format.

Assistance in ICTs skills development

Some of the networking projects have taken cognizance of the fact that just helping libraries to automate is not enough; this must be backed up with provision of appropriate skills to manage the networks as well as to ensure optimization of resources accessed. Consequently, developing ICTs skills for personnel in member institutions to enable them participate fully in the information technology environment has become a major undertaking alongside other implementation issues. This is given impetus by the fact that there is always shortage of ICTs skilled personnel in our libraries and information centres.

An important trend in the provision of ICTs skills is that many of the networks are targeting skills development in specific areas. For example, KENET aims to develop skills to enable document processing, specifically paper-to-electronic format conversion. Similarly, PERl's focus is on providing awareness or training in the use, evaluation and management of ICTs. Indeed, one of the core ways through which PERI provides support to librarian communities is the 'enhancing ICT skills' component.

eSAP also has been actively involved in providing training for academicians to be able to utilise the Internet resources as a prerequisite for successful access and use of available e-resources. Even DATAD has put some effort in this regard through creating capacity in universities for the collection, management and dissemination of theses and dissertations electronically.

However, AVL-K appears to be the only one that has implemented a structured ICTs training for its member institutions. The project has developed a curriculum for post-graduate diploma in information management in conjunction with the Kenya Institute of Management with the purpose of training young African graduates to spearhead information revolution in Africa. According to Kinyanjui (2000), the training programme offered by distance learning through the African Information and Communication Technology Institute (AICTI), an initiative of the AVL-I, is designed to produce information managers who will constitute the nucleus team to work towards a new approach to information management in Africa.

\section{Shortcomings}

Although some gains have been realised with regard to information sharing through networking, the road has not been easy. Indeed, a study by Onyancha and Ocholla (2006) indicates that there are very poor inter-university linkages in Kenya with majority having only one web inter-connection. This presents a significant drawback in the successful implementation of resource sharing and could be attributed to a number of factors.

First, many of the potential participating institutions are still struggling to automate their libraries and this no doubt impacts on the individual institution's ability to fulfil their tasks and responsibilities. As Wanyoike (2004) observes, the magnitude of the task to mobilise libraries to automate and network almost from scratch is tremendous in view of the various administrative and financial difficulties associated with institutions in the country.

Libraries are also required to first build and maintain their electronic databases before they can begin to think of sharing the information resources jointly owned by the cluster. Yet, many of the projects are initiated with the assumption that individual institutions have the capacity to create and maintain databases necessary for networking as well as the means to implement electronic communication facilities.

The lack of capacity is mainly as a result of inadequate resource allocation for information services. This is exemplified by the fact that public universities in Kenya (as indeed in many sub-Saharan African countries) depend on national governments to fund $90 \%$ of their recurrent and capital budgets (Raseroka, 1998). Consequently, when economic fortunes take a downturn, funding for these institutions go down considerably, occasioning serious decline in service delivery. This is made more difficult by the fact that member institutions are obligated to provide resources for sustenance of any network project.

For example, each university participating in eSAP must implement a financial write-off system for the project equipment where the project finances the initial purchase of the essential technical equipment, but individual universities undertake to help make the project sustainable by, among other things, replacement or renewal of the equipment. These resources are sometimes difficult to secure from university administrators.

The cost of connectivity is another major problem which is left to the participating institutions to handle for themselves. Except for a few initiatives such as KENET which has an arrangement with Telkom Kenya to offer lower tariffs (up to $50 \%$ of the commercial rates) for subscribing institutions, other networks do not have such initiatives. Consequently, a good number of institutions which qualify for membership have not been connected due to the high cost of bandwidth and infrastructure. Moreover, even for those institutions that are already connected, there has been 
discontent with insufficient bandwidth allocated to them which causes slow system response occasioned by congestion especially during peak hours.

There has also been a high turnover of expert staff both at the networks' as well as at the institutions themselves which has slowed implementation of some activities envisaged by some of the networks. For member institutions, inadequately trained manpower to properly manage the networks' services has been a major stumbling block to successful implementation and sustainability. A case in point is KENET which has yet to implement one of its key services relating to repackaging of local content in electronic format and sharing across the Internet, which would greatly assist in information resources sharing.

For some of the networks, problems arise due to limitations placed in accessing the databases. For example, in order to have full access to the DATAD database, users need to subscribe or connect from a subscribing institution. This presents a hurdle for resource sharing because a researcher must be affiliated to an institution that is registered in order to enjoy the privilege and low cost of collective membership.

Another factor that hinders successful implementation of many of the initiatives is lack of clarity on how to respond to requests for full text. Materu-Behitsa (2004) opines that in the case of DATAD this is possibly due to absence of clear policies on copyright and access provisions. This could as well be true of many of the other initiatives. There is also lack of clear strategy for implementation of sound preservation policy for electronic copies of works from participating institutions, which is essential to ensure long-term availability. Even though this has been noted especially for DATAD (Materu-Behitsa, 2004a) this is a problem that affects all local networks and this represent an obstacle to the success of the initiatives.

Significantly also is the selfish attitude among universities in Kenya as each one tries to gain a more competitive advantage with regard to increasing their enrolment figures. For example, Onyancha and Ocholla (2006) found that one of the reasons for the poor collaboration among Kenya universities (attributed to one computer science lecturer) was that the universities are competitors and cannot therefore advertise each other's services, products, or even curriculum on their websites.

Nevertheless, it would appear that many of shortcomings are identical for all the existing electronic information sharing initiatives essentially because they operate in similar information environments. There are both structural and conceptual problems. Were's (2004) concerns with regard to the challenges that KLISC has to contend with if the consortium is to succeed embodies the challenges that all other networks grapple with. These include: sustainability; change of priorities (say from building collections to enhanced access); provision of reliable connectivity; insufficient and costly bandwidth; lack of technical know-how, and low level of technological infrastructure.

\section{Conclusion}

This paper has addressed itself to some of the major information resources sharing initiatives in universities in Kenya. The increase in the value and demand of information continues to exert pressure on libraries to offer more effective service to their users. There is no doubt that the advent of ICTs has brought about a complete revolution to the library's traditional roles of retrieval and dissemination of information. In view of the liberalisation of information provision through ICTs, information services are beginning to shift focus from accumulation and ownership of information resources, to providing access, hence the emergence of many online initiatives.

Although on-line information sharing networks are not a panacea to all the problems facing information providers in these institutions, they are, nevertheless, expected to open new avenues, enabling users to have access to vast information resources available within international databases. Such initiatives have had their share of successes and failures. The absence of clear policies and institutional commitment in providing the necessary infrastructure has slowed the process of establishing a national information network envisaged by many of these initiatives. Libraries and information centres in our universities have also had to deal with their internal problems, especially lack of funding.

However, there are very good indicators that on-line information has started to play a significant role in addressing the issue of information scarcity in the universities, as evidenced by the achievements of such projects like PERI and KENET. In order for such initiatives not to appear to be 'initiatives of the future', Kenyan universities must make serious commitment in investing in ICTs infrastructure and provision of sufficient resources to enable more effective and efficient information resources sharing. Moreover, focus should be more on scaling up activities that have been successful rather than those that may retard progress.

\section{References}

Association of African Universities (200I). Database of African Theses and Dissertations - DATAD. [Online] available: http:// www.aau.org/datad. (Accessed August 15, 2005).

SA Jnl Libs \& Info Sci 2007, 73(I) 
African Virtual University (AVU, 2004). AVU digital library. [Online] available: http://www.avu.org/section/library.cfm? (Accessed February 24, 2006).

The African Virtual University (AVU, 2005). About AVU. [Online] available: http://www.avu.org/ (Accessed November 4, 2005).

Ayoo, Philip O (2005). The IUCEA brings together East African universities to undertake joint research in open source software for egovernment.. [Online] available: http://www.iucea.org/show_news_details.php?item_id $=10$ (Accessed July 10, 2006)

Board of Trusteess of the Leland Stanford Junior University (2004). African Virtual Library initiative. [Online] available: http:// www.sul.stanford.edu/depts/ssrg/africa/libaf.html (Accessed November 20, 2005)

International Network for the Availability of Scientific Publications (INASP, 2005). Programme for the Enhancement of Research Information (PERI). [Online] available: http://www.inasp.info/peri/intro.shtml (Accessed December I2, 2005).

International Federation of Catholic Universities (IFCU, 2005). Electronic supply of academic publications to and from universities in developing regions (ESAP). [Online] available: $h t t p: / / w w w . f i u c . o r g / i a u p / e s a p /$ (Accessed December 14, 2005).

Internet Foundation - Kenya (2002). African Virtual Library Initiative. [Online] available: http://www.inasp.info/peri/intro.shtml (Accessed November 20, 2005).

Inter-University Council of East Africa (IUCEA, 2004). About IUCEA. [Online] available: http://www.iucea.org (Accessed November 2, 2005).

IUCEA (2005) Member Institutions. http://www.iucea.org/General_Public/member_universities.php (Accessed July 10, 2005).

Jensen, Mike. (1998). African Internet connectivity: summary of international ICT development projects in Africa. [Online] available: http://www3.sn.apc.org/africa (Accessed November 8, 2005).

Kamau, N. (2002). Breaking Information Access Barriers: the African Virtual Library Initiative (AVL-I). [Online] available: http:// www.hipnet.org/ppt/200I/kamau/sld0/4.htm (Accessed December I5, 2005)

Kenya. Commission for Higher Education (CHE, 2006). Accredited Universities. [Online] available: http://che.or.ke/ accreditation.html (Accessed June 20, 2006).

Kenya Education Network (KENET, 1999). About KENET. [Online] available: http://www.kenet.or.ke/ (Accessed November 4, 2005).

Kinyanjui, William (2000). The African Virtual Library Initiative (AVL-I): the strategy for information management for sub-Saharan

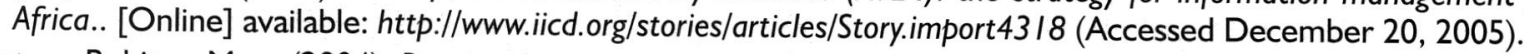

Materu-Behitsa, Mary (2004). Resources to support research in Africa: the Database of African Theses and Dissertations (DATAD). [Online] available: http://www.sist-sciencesdev.net/fichiers/Seminaires/Presentations_Accra/DATAD.ppt (Accessed December 16, 2005).

Materu-Behitsa, Mary (2005). Database of African Theses and Dissertations (DATAD): copyright and IPR management challenges.

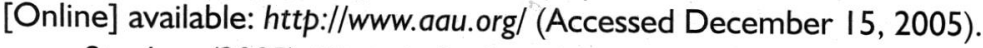

Mayega, Stephen (2005). The supply of academic publications to and from universities in the developing regions by means of Internet. [Online] available: $h t t p: / / w w w . a e p i c . i t / c o n f / v i e w p a p e r . p h p ? i d=57 \& p r i n t=1 \& c f=3$ (Accessed December 14, 2005).

Ocholla, Dennis (1995). Professional development, manpower education and training in information sciences in Kenya. [Online] available: $h t t p: / / c e r e s$.emeraldinsight.com/vl=34/80/4=48nw $=I / f m=h t m l$ (Accessed August I6, 2005).

Odini, Cephas (1991). "Problems and prospects of resource sharing in developing countries." African Journal of Library, Archives \& Information Science, Vol. I, No.2, pp. 93-98.

Onyancha, O.B., Ocholla, D.N. (2006). African institutions of higher learning: ripe for cybermetric studies? Performance of South African and Kenyan universities on the World Wide Web. Paper presented at the $8^{\text {th }}$ Annual Conference on World Wide Applications held on $6^{\text {th }}-8^{\text {th }}$ September 2006, at the University of the Free State, Bloemfontein, South Africa.

Raseroka, H.K. (1998). "Skills for information professionals in academic libraries in sub-Saharan Africa." In Information for sustainable development in the 2 Ist century: proceedings of the $13^{\text {th }}$ Standing Conference of Eastern, Central and Southern Africa Librarians, $27^{\text {th }}-31^{\text {st }}$ July. Nairobi: Kenya Library Association.

Simons, Eduard (2001). S.A.P.: the supply of academic publications to and from universities in developing countries. [Online]

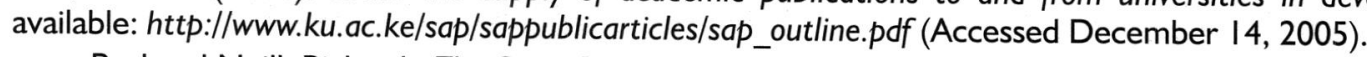

Sturges, Paul and Neill, Richard: The Quiet Struggle: Information and Libraries for the people of Africa. $2^{\text {nd }}$ ed. Masell: London and Washington, 1998, p. 168.

Thairu, Henry M. (2004). Kenya Education Network (KENET): interconnecting academic and research institutions for the sharing of

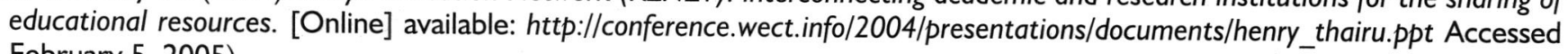
February 5, 2005).

Ubogu, Felix N. (2003). From DATAD to ETDs: the way forward. [Online available]: http://edoc.hu-berlin.de/conferences/etd2003/ ubogu-felix/PDF/index.pdf (Accessed December 16, 2005).

Wanyoike, John (2004). The camel comes of age: academic and public libraries' partnership in sharing information through information technology in Kenya - the role of African Virtual Library project. [Online] available: http://www.ala.org/ala/iro/ iroactivitiescamecomesage.htm (Accessed August 20, 2005).

Were, J. (2004). Getting affordable access to scientific information for teaching and research: experience of Kenyan universities. [Online] available: $h t t p: / / w w w . i n a s p . i n f o / s y m p o s i u m / 2004 / S y m p-2-2-W e r e . p p t$ (Accessed December 16, 2005)

Wolff, Laurence (2002). The African Virtual University: the challenge of higher education development in sub-Saharan Africa. TechKnowLogia, Issue Number 16, April-June. [Online] available: http://www.techknowlogia.org/ (Accessed November 2, 2005).

World Bank Group (1998). The African Virtual University. [Online] available: http://www.worldbank.org/wdr/wdr98/africa/ bpafr9.htm (Accessed November 12, 2005) 